\title{
Design and Implementation of a Website for Road Transport Operators and Travellers in Nigeria
}

\author{
Muhammad-Bello, Bilkisu Larai \\ Information and Media Technology Department, \\ School of Information and Communications Technology, \\ Federal University of Technology Minna, Nigeria.
}

\begin{abstract}
The integration of Information and Communication Technologies (ICT) in the transportation sector has resulted in organized and effective transportation services in many developed societies. The road transportation system in Nigeria is un-coordinated and has resulted to inefficient public transportation services. Previous studies have identified the problems of the Nigerian road transportation sector with intent to offering an optimal solution using Information Technology (IT). The scope of IT in creating an enabling and a suitable business environment in form of a website which would bridge the gap between the transport companies and independent travellers whilst meeting real business needs has also been explored. Thus, this paper focuses on the design and implementation of the prototype of a commercially viable web portal for Nigerian road transport operators. The operational prototype developed was also tested and evaluated by the two major stakeholders.
\end{abstract}

\section{General Terms}

Web Development

\section{Keywords}

Transport operators, Nigerian road transportation, Commercial viability, Web Design.

\section{INTRODUCTION}

An efficient transport system is an essential ingredient for a thriving and growing economy. The road transport management system in Nigeria is poor and ineffective and has resulted to inefficient public transportation services [1]. There is lack of information on the schedules and routes of the transport service companies in Nigeria. Travellers therefore need to physically visit the transport companies just to make advanced bookings and also to get the basic travel information needed. This has also resulted to lack of business communication for the transport companies. Travel in Nigeria is thus problematic and painful for many as it is frequently stalled by inconveniences and inefficiencies due to the problems and uncertainties associated with travel in Nigeria especially via public transportation [2].

At the same time, there is rapid urbanization taking place in the country, as Nigerians are gradually embracing the use of IT and IT based services in their daily lives. Statistics has estimated Nigeria to have over 67 million Internet users as at December 2013, which constitutes about $38.0 \%$ of the population [3]. In another recent survey conducted by the Nigerian Stability and Reconciliation Program (NSPRP) of the British Council, it was revealed that Nigeria had 62 million Internet users as of the end of 2013 and the number expected to increase in years to come [4]. A study of traveler's perceptions on the application of information technology in the Nigerian road transportation sector was investigated in [5]. In addition, a business model which exploits the power of IT and also captures the value created whilst effectively meeting the demands of the major stakeholders was proposed in [6].

Consequently, this paper gives a report on the design and implementation of a prototype website which effectively meets the needs of the stakeholders whilst evading most of the problems identified in [5]. The information gathered during the problem investigation stage was used to develop a plan for this study. The findings from previous works were translated into requirements specifications for the web portal.

\section{EVIDENCE-BASED FUNCTIONAL REQUIREMENTS}

A detailed functional requirement specification was put together based on the user needs identified during the problem investigation stage and the business needs reviewed in previous works [5], [6]. A summary of the evidence-based needs are outlined as follows:

i. The need to allow transport companies to register on the website.

ii. The need to allow travellers to search for travel information

iii. The need to allow travellers to book/buy tickets online.

iv. The need to allow transport companies to upload schedules.

v. The need to allow transport companies to upload other important information.

vi. The need to allow transport companies to advertise on the website.

vii. The need to allow stakeholders to communicate with each other.

The approach taken for this study was to capture the requirements of an ideal travel website without too much concern about the implementation phase. Thereafter, the requirements captured were prioritized based on their importance and their overall impact on the study. This method ensured that the most important requirements were the first to be implemented such that the end users would have a sense of appreciation for the end product being of value to them.

Table 1 summarizes the functional requirements which have been prioritized based on the evidence-based needs. Associated with each functional requirement is a priority number $(\mathrm{P})$ and a link to the needs $(\mathrm{N})$ outlined above. The outlined needs are numbered 1-7 while a number ranging from 1 to 3 is associated with each $(\mathrm{P})$. ' 1 ' indicates essential and very high priority, ' 2 ' indicates preferred and medium 
priority while ' 3 ' indicates that the feature would be nice to have thus, low priority.

Table 1: Summary of Functional Requirements

\begin{tabular}{ll}
\hline Functional Requirement & $\begin{array}{l}\text { Priority } \\
\text { \&Evidence Based Need }\end{array}$ \\
\cline { 2 - 2 } $\begin{array}{l}\text { Account Creation } \\
\text { Time table upload and other } \\
\text { travel information }\end{array}$ & P1, N4, N5 \\
Search Facilities & P1, N2 \\
Online Payment & P1, N3 \\
Feedback Page & P2, N7 \\
Contact Page & P2, N7 \\
Forum & P3, N7 \\
Banner Advertisements & P3, N6 \\
\hline
\end{tabular}

\subsection{Description of Functional Requirements}

- Creating an account (P1, N1): For the transport companies, they should be able to create a personalized account by registering on the website. In addition, the system should be able to verify that each company's name is unique, and if there is an attempt to register a company name or username that is already in existence, the system must automatically alert the user. Furthermore, the system should automatically check the password provided and ensure there is concordance. The system should also alert the user if there is a mismatch. Finally, the Terms \& Conditions must be read and agreed to before the registration process is completed.

- Uploading Time table and other travel information (P1, N4, 5): A form should be provided for the transport companies to complete in order to upload germane travel information.

- Searching Facilities (P1, N2): A search facility must be provided to allow travellers search for the transport companies, their offerings and other travel information. In addition, they should be able to click on a search result to view details, make a selection and book a trip.

- On-line payment (P1, N3): An online payment system should be provided on the website for both the travellers and the transport companies. The transport companies should be able to pay online either with a credit card or through bank payment while registering. On the other hand, travellers should be able to pay for tickets online. The online payment functionality will be in partnership with services like Interswitch, MasterCard and PayPal to guarantee the security of all transactions on the website.

- Feedback Page (P2, N7): A feedback or comment form should be provided for travellers to be able to contact transport companies and give valuable feedback on their experiences and also suggest ways to improve their services. The messages sent through the feedback form should be forwarded to the email addresses of the respective transport companies.

- $\quad$ Contact page (P2, N7): A form should be provided on the contact page for both travellers and transport companies to be able to contact the business. The messages sent through the form should be forwarded to the site administrator's email address.

- $\quad$ Forum (P3, N7): The forum should be available to travellers, allowing them to post comments on the transport companies' profiles.

- Banner advertisements (P3, N6): Provision should be made for displaying banner advertisement on some of the pages of the website especially the search result pages.

\subsection{Description of Non-Functional Requirements}

The Non-functional requirements define the overall qualities or attributes of the resulting website [7]. A study of corporate websites revealed that $90 \%$ of commercial websites had poor usability and this tends to affect customers loyalty which often leads to failure of such websites [8]. The poor usability of some sites has been attributed to lack of implementation of basic non-functional requirements of an ideal web portal [9]. For this reasons, the non-functional requirements were considered just as important as the functional requirements, and also given the highest priority (P1). Taking the Nielsen's heuristics into consideration [8], the following nonfunctional requirements were put together for the web portal.

- The user interface design: The user interface should be visually appealing to the user as it is the part of the website with which users interact with the system. The user interface design must be user friendly and should be able to support multiple users and purposes

- Website Layout: There should be consistency in the use of colours, fonts, and icons for the layout of the website. The layout should not be complicated, and should be in in a way that will assist users in navigating the website. The navigation should have a clear pattern and must also be very efficient in order to help users find what they want easily.

- Real world representation: The website should act in accordance with the real world, by using concepts, words and phrases that are consist with the users' real world knowledge about the transportation sector in Nigeria.

- Content Presentation: The contents should be delivered in a concise and organized manner. This will ensure that site users are not overwhelmed by the information on the web pages.

- Compatibility with Multiple browsers: The website must conform to standards and be compatible with many of the available web browsers. This requirement will ensure that site users are able to use any web browser to access the site.

- Accessibility: The website should be readily accessible 24hours a day in order to guarantee access to site users at any time of the day. 
- Usability: Site users should be able to use website easily without requiring specialized trainings.

- $\quad$ The W3C Standards: The HTML and CSS codes used in the design and implementation must conform to the W3C (World Wide Web Consortium) standards.

\subsection{Requirements Specification Model}

The tasks for the design were broken down into modules in other to effectively capture the functional requirements of the website to be developed. The first module captures the activities of the system administrator; the second module captures the functional requirements of the travellers while the third module captures the functional requirements of the transport companies. The functional requirements model is depicted in Figure 1 below.

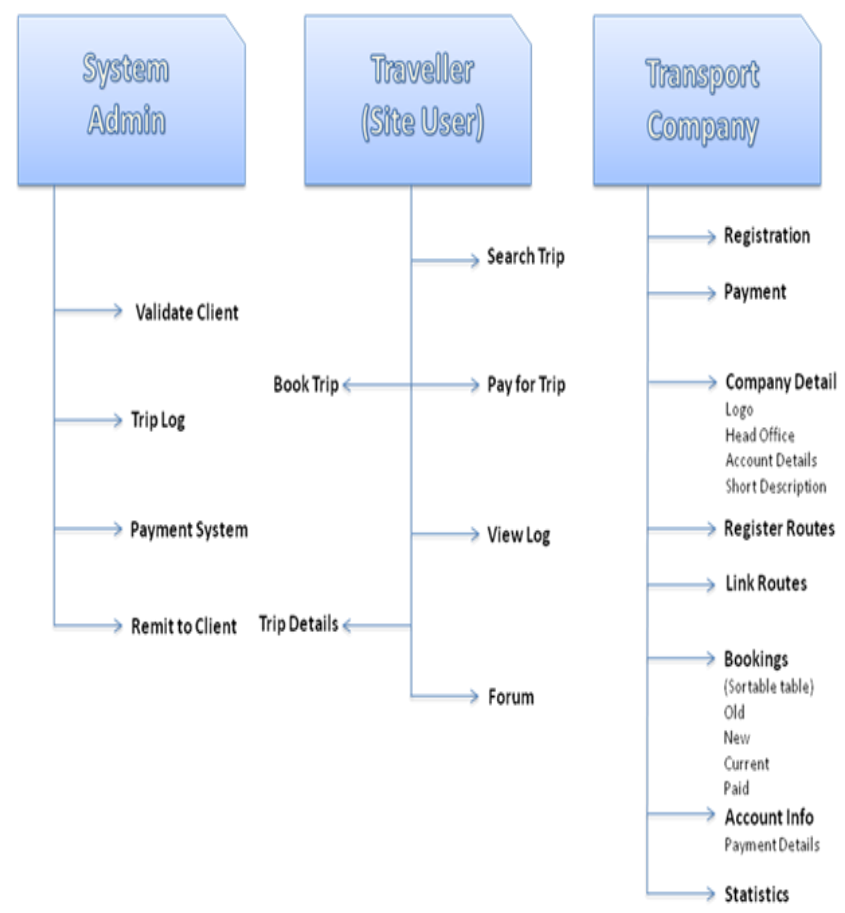

Figure 1: Requirements Specification Model

\section{METHODOLOGY}

\subsection{Software Development Model}

The Spiral Software Development Model was adopted. The spiral model was chosen because it is particularly suitable for creating websites. More so, it combines some key features of the both the waterfall model and the prototyping model whist reducing the weaknesses and limitations of both models. The spiral model is also a risk-reduction oriented model that breaks a software project up into mini-projects, each addressing one or more major risks [10].

Prototype A would be a quick design based on the identified objectives. PrototypeB would be an improvement on Prototype1; it would incorporate all the required features for both the travellers and the transport companies. The third iteration would involve the development of PrototypeC which would be subjected to real life testing by a few stakeholders to verify its correctness. Feedback would be taken and used to improve on Prototype3. This would lead to the final iteration, which has the Operational Prototype as its deliverable.

\subsection{Web Architecture}

The web architecture of a website outlines the structures needed to reason about the operations of the website, which comprise software elements, connections between them, and properties of both. It also refers to the documentation of a system's software architecture [11]. The three-tier model was adopted for the web architecture. This is because it is a clientserver architecture in which the presentation, the application processing, and the data management process are logically separate processes. The three-tier model is particularly suitable for web development usage such as e-commerce websites which are built using three tier; the front end, the middle tier and the backend.

The website to be developed requires that a user interface, a functional process logic (business logic), and a database be developed and maintained independently on separate platforms

\subsection{Software Package and Programming Languages}

WAMP is an acronym for a set of open source applications combined with the Microsoft Windows Operating System. The WAMP acronym stands for Windows, Apache, MySQL and PHP. The WAMP package was chosen because it consists of independently-created programs that can be installed on computers that use the Microsoft Windows operating system and it is also an open source project which is free to use.

The other tools used for the design and implementation phase are as follows:

- Adobe Photoshop CS5: for developing the webpage layout i.e. the User Interface design

- Adobe Dreamweaver for writing the HTML, CSS, JavaScript and PHP codes.

\section{DESIGN}

\subsection{User Interface Design}

The user interface was designed using Adobe Photoshop CS5. The homepage was designed to include a header and footer section. The header section contains the logo, the navigation bar and some photos depicting the essence of the website. The main body contains a brief description of the business solution the website is offering for both the transport companies and travellers. It also contains a search facility for travellers. The footer section contains links to the Twitter and Facebook pages of the website.

\subsection{Database Design}

The database was designed with a total number of 16 tables after a thorough analysis of the entities and the relationships between them. The schema diagram depicted in Figure 3 below shows a summary of the entities and the relationships between them. 


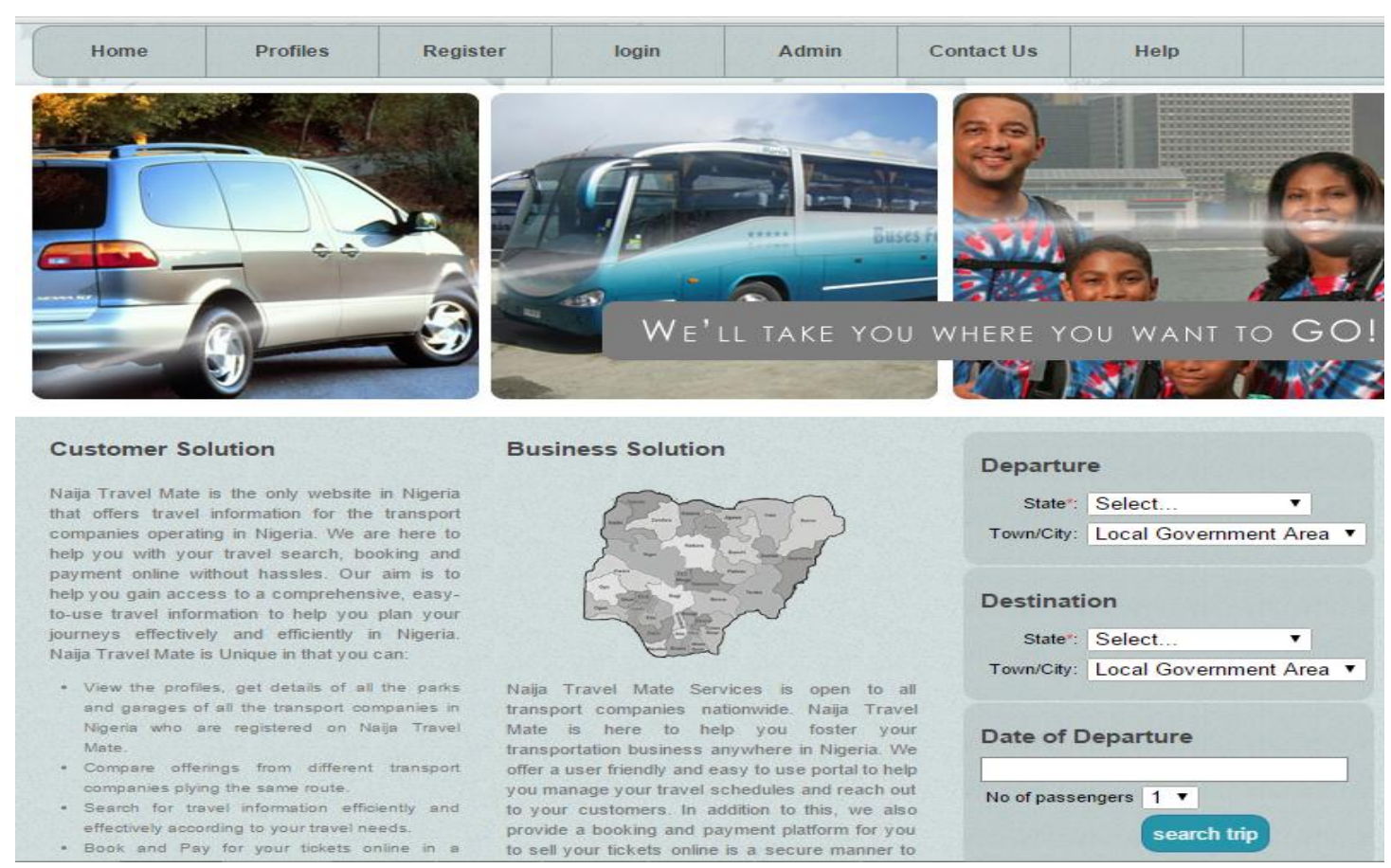

Figure 2: The Home Page

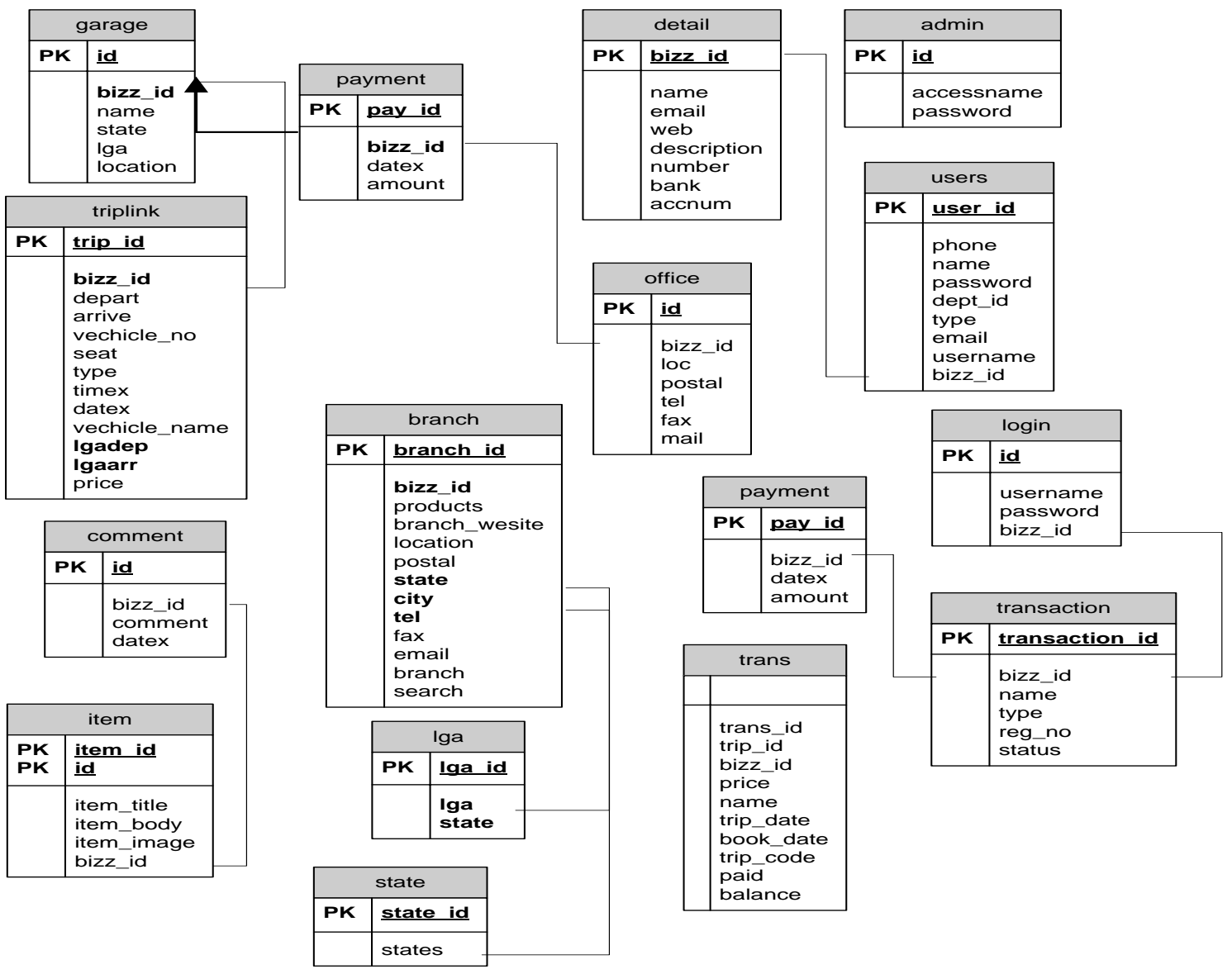

Figure 3: The Database Schema 


\section{RESULTS AND DISCUSSION}

\subsection{Walkthrough}

The walkthrough for the activities of both the transport companies and travellers on the website is presented in this section. The sitemap for the operational prototype is depicted in Figure 4.

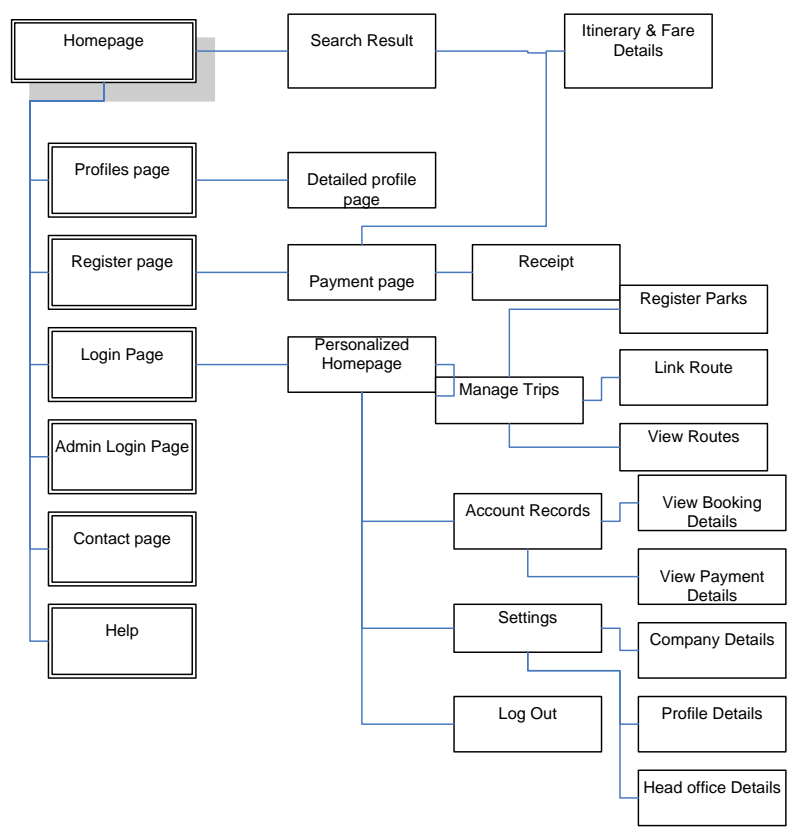

Figure 4: Sitemap of the Website

\subsubsection{Registration}

\subsubsection{Creating an Account}

The transport companies are required to create an account before they are able to use the website. Upon clicking on the registration link on the homepage, users are asked to create an account by entering some personal details in the required fields. Once the form is submitted, three types of checks are run by the system before inserting the details into the database. First, the system checks if all the fields have been entered, then it checks the uniqueness of the Company Name and the Email in the database. Finally, it checks for possible mismatch in the passwords entered. The user is notified immediately if any of these checks fail. The system also prompts users to check the "Terms and Conditions" check box before allowing them to proceed further to make payment.

\subsubsection{Making Payment}

In other to complete the process of creating an account, the transport companies have to make payment on the payment page depicted in Figure 5. There are two payment options on the prototype website; online payment with credit cards and also the bank payment option. The payment completes the process of creating an account for the transport companies. A receipt which contains a unique Transaction ID is generated to confirm the payment. A sample of the payment receipt generated is depicted in Figure 6.

\subsubsection{Login Page}

After making payment, the transport companies can proceed to the Login Page to login with their email address as user name and the password entered during registration process.
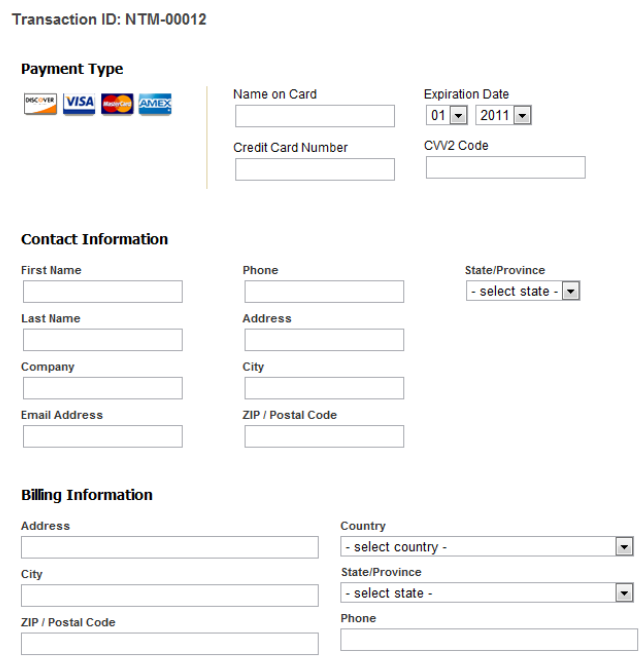

submit

Figure 5: Payment Page

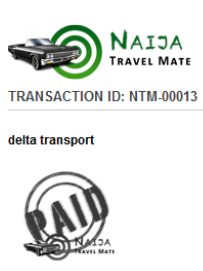

Figure 6: Sample of Payment Receipt

\subsubsection{Personalized Home Page}

Once the transport companies login, they are able to view their personalized home page depicted in Figure 7 which contains the following sections: a header which contains the navigation bar and the name of the transport company. The body contains a comments section which shows all the recent comments posted by travellers on the transport companies' profiles. The body also contains a recent bookings section which summarizes all the recent bookings made. The statistics section shows the total number of bookings, the total number of garages/parks registered by the company, the total number of comments on their profile page and the total payments remitted.

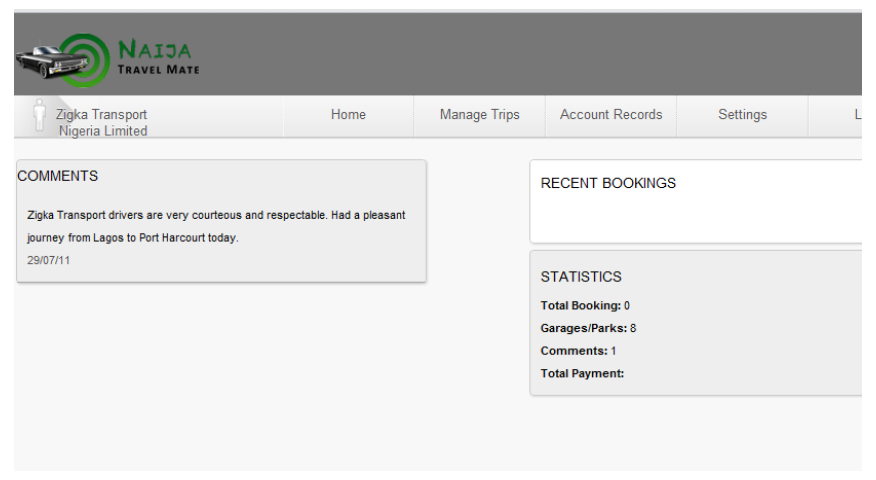

Figure 7: Personalized Home Page 


\subsubsection{Company Details Registration}

Upon clicking on the settings link and selecting the Edit Company details option, the transport companies can enter the full Company details. The details include the email address, Company website, Bank, Account Number and a Brief Description of the transport company. They can also reset their profile details such as the password on the same page.

Upon clicking on the Settings link and selecting the Head Office option, the transport companies can input the details of their head offices. The details include the location, postal address, telephone, fax and email address.

\subsubsection{Managing Trips}

\subsubsection{Registering Parks and Garages}

Upon clicking on Manage Trips and selecting the Register Park/Garage Option, the transport companies can register all their Parks/Garages nationwide. A summary of all the registered Parks/Garages along with the address of each Park/Garage will also be displayed. The transport companies can add all their new Parks/Garages, and also delete any previously registered Park/Garage that is no longer in existence. Figure 8 below shows a sample of the Parks/Garage registration page.

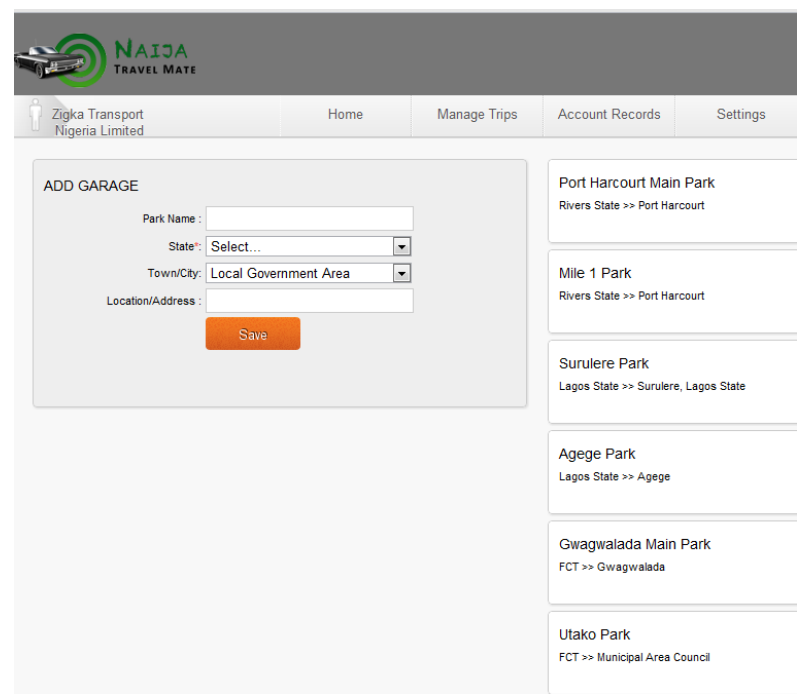

Figure 8: Parks/Garages Registration Page

\subsubsection{Uploading Time-Table}

Upon clicking on Manage Trips and selecting the Link Routes option, the transport companies can upload their travel schedule (time-table) by entering the details on a form. The form makes it easy for them to upload the time-table as all they need to do is select the departure and Destination point from the list of Parks/Garages. Next, the time is selected under the trip detail option. In addition to this, there is an option for them to indicate trips that re-occur on a daily basis, thus there is no need for them to keep uploading such details as the database automatically updates it as re-occurring. This option can also be deleted or modified later.

\subsubsection{Viewing the Time-Table}

A summary of all the trip schedules uploaded can be viewed by clicking on the Manage Trip link and selecting the View Routes Option. Invalid entries on the time-table can be deleted easily by a single click on the delete button link corresponding to the entry. A sample page is depicted in Figure 9.

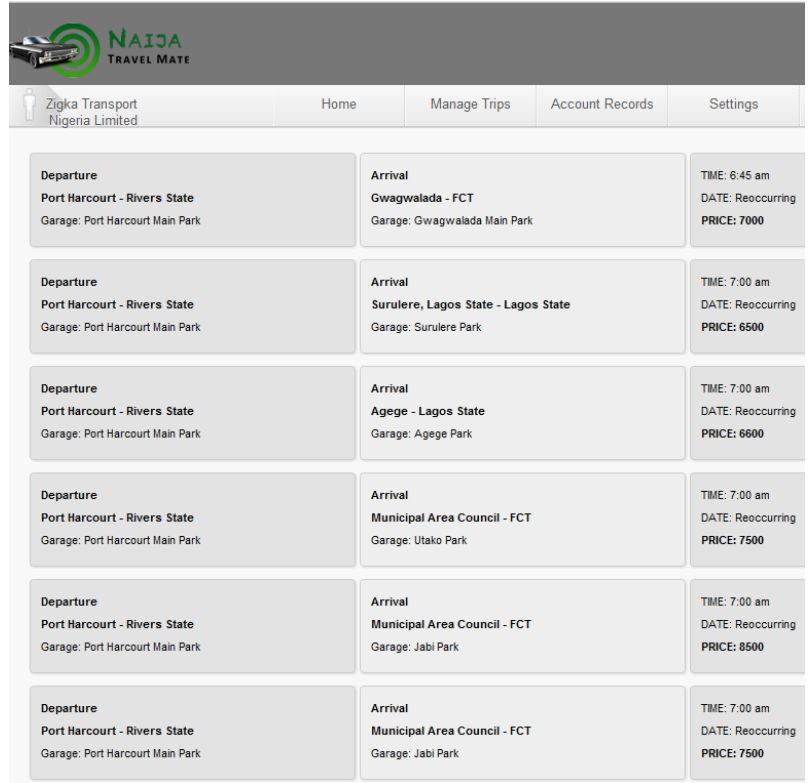

Figure 9: Viewing all available Routes

\subsubsection{Account Records}

Upon clicking on the Account Records menu, there are two available options: one option is for viewing Booking Details and the other one is for viewing Payment Details.

\subsubsection{Bookings Details}

The Booking Details option shows a comprehensive list of all the bookings made.

\subsubsection{Payments Details}

The Payment Details option displays a comprehensive record of all the payments that have been remitted to the transport company.

\subsubsection{Search}

From the homepage (see Figure 2), travellers can easily search for travel details by entering the search criteria on the search form located on the home page. Upon submitting the form, the database is queried and matches are displayed in the search result page depicted in Figure 10. Each transport company is shown as a separate record with the following details: From, to, departure time, Vehicle type, and price.

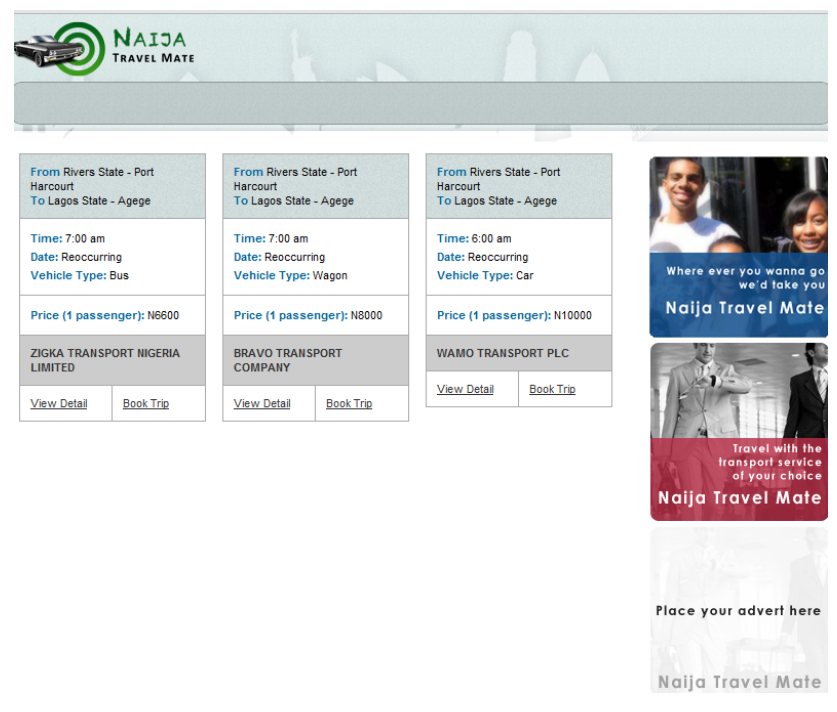

Figure 10: Search Results with Banner Ads 


\subsubsection{Itinerary and Fare Details}

Upon clicking on View Details, details of the search are displayed to view the travel itinerary and fare details as depicted in Figure 11.

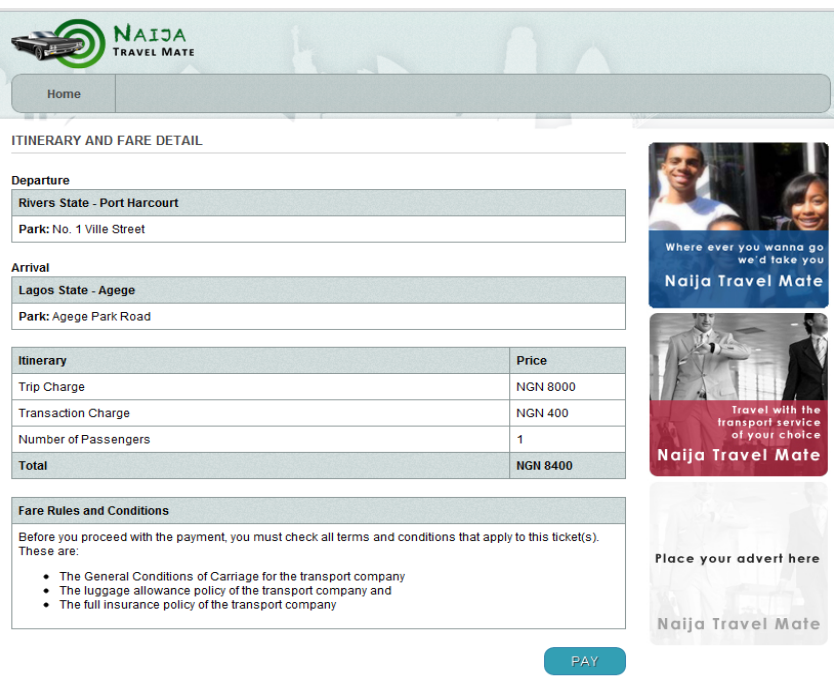

Figure 11: Itinerary and Fare Details Page with Banner Ads

\subsubsection{Payment Page}

Travellers can make a selection and proceed with the booking which takes them to the payment page.

\subsubsection{Payments Receipt}

A payment receipt is also generated at the end of each transaction for the travellers to print and present at the parks/garages before departure.

\subsubsection{Banner Adverts}

Web users are exposed to lots of advertisements on the internet, so there is always a tendency for people to screen out most of the information they are exposed to especially on the homepage. For this reason, the banner advertisements have been strategically placed on the search result pages. This is to ensure that site users get to see the adverts and also reduce the tendency of them screening out the information as they would be interested in the contents of the search result page and the itinerary and fare details page.

\subsubsection{Viewing Profiles of Transport Companies}

Upon clicking on the profile link on the homepage, a summary of all the transport companies registered on the website is displayed. Details of each transport company can be viewed by clicking on the "view details" link. The profile page is shown in Figure 12 and Figure 13.

\subsubsection{Viewing Schedules}

Upon clicking on the view schedule link, a detailed trip schedule (time-table) of the transport company is displayed. This time-table is comprehensive and can be viewed by travellers without necessarily initiating a search on the website.

\subsubsection{Contact Form}

Upon clicking on the "contact us" link on the navigation bar, a contact form is displayed for travellers, transport companies, advertisers and other site users to contact the site administrator and all messages are directed to the site administrator's mailbox. The contact page is depicted in Figure 13 below.

\begin{tabular}{|c|c|c|c|c|c|c|}
\hline Home & Proffles & Register & login & Admin & Contact Us & \\
\hline & & & & & & View detail \\
\hline \multicolumn{6}{|c|}{ Mfy Transports } & View detail \\
\hline \multicolumn{6}{|c|}{ Alpha Nigeria Transport Company Limited } & View detail \\
\hline \multicolumn{6}{|c|}{ Bravo Transport Company } & View detail \\
\hline \multicolumn{6}{|c|}{ Zigka Transport Nigeria Limited } & View detail \\
\hline \multicolumn{6}{|c|}{ Wamo Transport Plc } & View detail \\
\hline \multicolumn{6}{|c|}{ Delta Transport Plc } & View detail \\
\hline
\end{tabular}

Figure 12: Profile page showing all registered transport companies



Figure 13: Profile Page showing details of a registered transport company

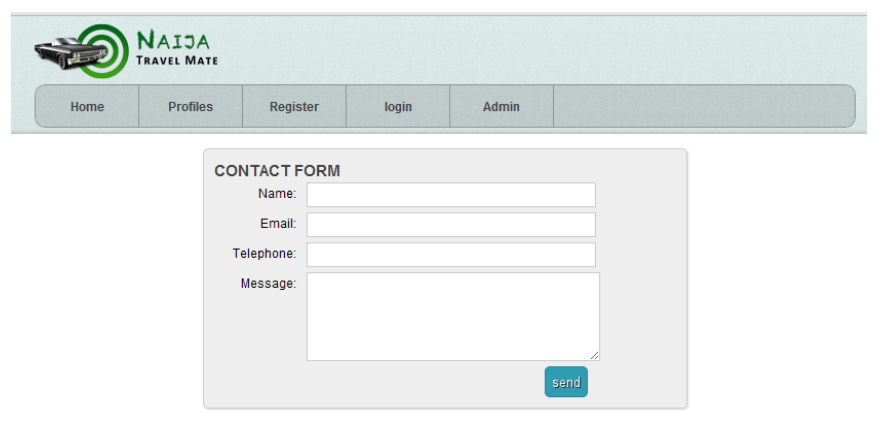

Figure 14: Contact form page.

\subsection{Evaluation}

In order to measure the users experience and ascertain whether the website meets the requirement specifications earlier identified, an evaluation exercise was carried out. The exercise provided insight to the accessibility of the functionalities of the website and also areas of possible improvements. Two separate task sheets were developed for both the travellers and transport companies. Subsequently, an evaluation sheet covering both the usability and functionality 
of the website was provided for the evaluators to complete. The results of the exercise are summarized in Figure 15 below. Each evaluation question was assigned a score between 1 and 5 ( 1 being the minimum and 5 being the maximum) by each evaluator. The vertical bars represent the total points on each of the evaluation questions.

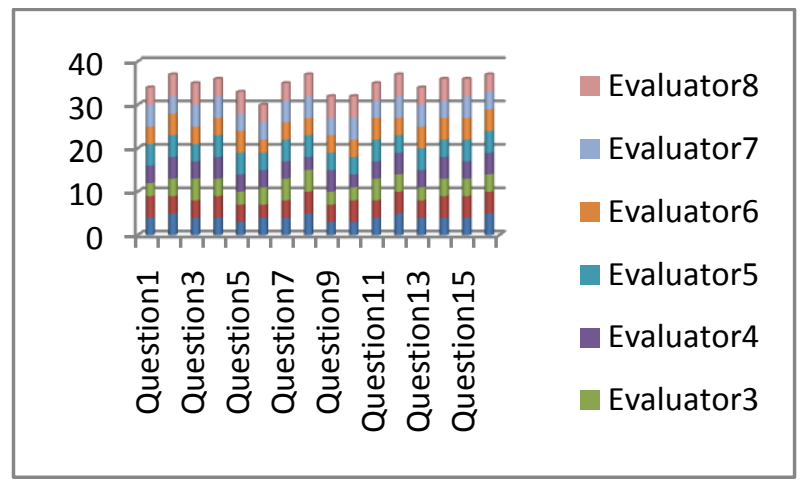

Figure 14: Evaluation Results.

Questions 1 to 8 addressed the usability assessment. The participants were pleased with the design, clarity of information and usability requirements giving it a mean score of 4.2 out of 5 possible points. All the participants were able to finish the assigned tasks, nevertheless, $60 \%$ of them could not complete the tasks under 15minutes thus Question 6 scored the least number of points. This was however attributed to fact that the participants were not familiar with the website and also due to the fact that it was the first time they were participating in such an exercise.

Questions 9-14 addressed the functional requirements of the website, and a mean score of 4.25 was recorded. The feedbacks from the participants were mostly positive. All the evaluators agreed that the website depicts a typical travel website and that it was easy for them to find the required travel information. The booking and payment functionality was perceived to be adequate. The need for more elaborate schedules was emphasized by some of the evaluators. This is however dependent on the number of transport companies registered and how robust their schedules are.

Responses to questions 15 and 16 had a mean agreement rating of 4.6 indicating that the participants were satisfied with the website and are likely to recommend it to other users.

\section{CONCLUSION}

This paper has presented the design and implementation of a prototype website road transport operators and travellers in Nigeria. The evidence based functional requirements as well as the non-functional requirements were discussed. The user interface design and the design of the database have also been discussed. A walkthrough of the website developed for the two major stakeholders as well as the evaluation results was also presented. Looking back to the critical success factors and the requirements specifications of the website, it is apparent that all the functional requirements of the website have been implemented which has captured the needs of both stakeholders in a meaningful way. The implementation of the forum functionality on the website could be improved upon in future work. In addition, a mobile application that builds on the functionalities of the website could be developed to provide easier access to travel information for travellers in Nigeria.

\section{REFERENCES}

[1] Muhammad-Bello B. L. (2011). Development of a Commercially Viable Website for Road Transportation System in Nigeria. Unpublished thesis (MSc), University of Manchester.

[2] Williams L., (2008). Nigeria: The Bradt Travel Guide. 2nd ed. Connecticut: The Globe Pequot press inc

[3] Internet World Stats (2014). Usage and Population Statistics: Africa. Retrieved from: http://www.internetworldstats.com/africa.htm. Last updated on November 6, 2014. Accessed on November 19, 2014.

[4] Umeh K. (2014). Survey reveals Nigeria had 62 million Internet Users in 2013. Retrieved from http://www.ngrguardiannews.com/news/nationalnews/183283-survey-reveals-nigeria-had-62-millioninternet-users-in-2013. Last updated on October 16, 2014. Accessed on November 9, 2014.

[5] Muhammad-Bello B. L. (2014). An Investigative Study of Travelers Perceptions on the Application of Information Technology in the Nigerian Road Transportation Sector. Academic Research International. Vol. 05, No 05, September, 2014. pp. 148-156.

[6] Muhammad-Bello B. L. (2014). Development of a Commercially Viable E-Business For Managing the Nigerian Road Transport System Based on the Information Technology (IT) Business Model. International Journal of Information Technology and Business Management. Vol. 27, No 01, July, 2014. pp. 148-156.

[7] Kotonya G. and Sommerville I (1998): Requirements Engineering: Processes and Techniques. Wiley \& Sons, 1998.

[8] Nielsen, J. (1998): 10 Usability Heuristics for User Interface Design Available online at: http://www.nngroup.com/articles/ten-usability-heuristics/ Accessed on November 10, 2014.

[9] Sommerville, I. (2007): Software Engineering. 8th ed. Harlow: Addison Wesley Ullman and Larry.

[10] Kuhl J.J. (2002): Project Lifecycle Models: How They Differ and When to Use Them. Business e-solutions Available online at: http://www.businessesolutions.com/islm.htm Accessed on November 10, 2014

[11] Clements P., Bachmann F., Bass L., Garlan D., Ivers J., Little R., Merson P. , Nord R. and Stafford J. (2010): Documenting Software Architectures: Views and Beyond, Second Edition. Addison-Wesley 2010. 